\title{
Elderly's Quality of Life in Daycare and Boarding Nursing Homes in Semnan, Iran
}

\author{
Alliakbar Pahlavanian, ${ }^{1}$ Mina Sadat Mirshoja, ${ }^{1,}$ Ziaeddin Safavi-Farokhi, ${ }^{1}$ Zahra Ahmadizadeh, ${ }^{1}$ and \\ Massoumeh Rasoulzadeh ${ }^{1}$ \\ ${ }^{1}$ Neuromuscular Rehabilitation Research Center, Faculty of Rehabilitation, Semnan University of Medical Sciences, Semnan, IR Iran \\ "Corresponding author: Mina Sadat Mirshoja, Neuromuscular Rehabilitation Research Center, Faculty of Rehabilitation, Semnan University of Medical Sciences, Semnan, IR \\ Iran. Tel: +98-2333322332, Fax: +98-2333654180, E-mail: msj5831@yahoo.com
}

Received 2015 July 01; Revised 2016 March 08; Accepted 2016 March 12.

\begin{abstract}
Background: Old age is a period of life in which elderlies face with complications such as increasing risk of chronic diseases, loneliness, isolation, mental and physical disabilities, and reduction of individual independence. These factors cause the quality of life to reduce.

Objectives: This study compared the quality of life of elderlies in daycare and boarding nursing homes in Semnan, Iran and identified the differences in characteristics of quality of life. It can also help researchers to reduce the problems of elderlies.

Materials and Methods: This cross-sectional study was performed on 30 elderlies living in boarding nursing homes and 43 in daycare nursing homes. Collecting the data was conducted via a special questionnaire(SF-36), measuring different aspects of quality of life.

Results: On the basis of SF-36 test and comparing various aspects of quality of life among the elderlies residing in boarding and daycare nursing homes, significant differences were observed in domains of quality of life, including physical restrictions $(\mathrm{P}<0.001)$, restrictions in psycho-emotional function $(\mathrm{P}<0.001)$, energy and fatigue $(\mathrm{P}<0.008)$, psycho-emotional function $(\mathrm{P}<0.001)$, social function $(\mathrm{P}<0.001)$, physical pain $(\mathrm{P}<0.001)$, and public health $(\mathrm{P}<0.01)$. However, the difference was not significant in physical function $(\mathrm{P}=0.437)$.

Conclusions: The results showed that the elderlies living in daycare centers had better qualities of lives physically and mentally. Therefore, to improve their qualities of lives in two general physical and mental domains, items such as providing family communications inside or outside the nursing homes as well as planning to fulfill mental and psychological needs besides physical issues like mobility and balance should be considered.
\end{abstract}

Keywords: Aging, Quality of Life, Nursing Home

\section{Background}

Quality of life is a key indicator and includes various aspects such as person's physiology, function and personality, and needs special attention. Medical developments improved life expectancy among the elderly in the second half of the twentieth century; consequently, the number of elderlies who need medical cares has increased (1). Iran, by undergoing a demographic structure change due to the census of 2006 , by having $7.27 \%$ elderly people above 60 years of age out of a 70 million population, has about 5119000 elderly people above the age of 60; in fact, it will be an aged country within the next 15 years and the percentage will rise to $10.7 \%$. According to the definition of the United Nations, when the population of elderlies is above $7 \%$, it is an aged country (2).

It is obvious that by increase of the number of elderlies, support, social, rehabilitation and health-care issues and problems will also increase. Today, more than $36 \%$ of the healthcare budget is spent on elderlies' health care (3). Elderlies face with special challenges such as increase in chronic problems, financial loss, and reduction of functional abilities. Therefore, it is not surprising that they need increased levels of support to remain independent (4).

Identifying the differences in characteristics of quality of life of elderlies can help researchers to perform studies, trying to reduce problems of elderlies. According to the latest official statistics, in Iran, the average life expectancy has risen to 67 years of age. According to statistics of 1996, the population above 60 years of age was four million and considering the census of 2006, this population is estimated to be 6.5 million (5). On the other hand, the growing number of elderlies in different communities is highly noticeable, so that it is called a silent revolution (6).

Old age is a period of life in which elderlies are exposed to potential threats such as increase of chronic diseases, 
isolation, loneliness and lack of social supports, and due to physical and mental disabilities their personal autonomy is threatened in some cases. These can lead to reduction in quality of life among them (7).

Old age is also a critical period in which special needs of elderlies, behaviors of health promotion and the quality of life must be under attention and should not be neglected (8). In fact, both prolonging life and promoting mental health need to be noticed. If they are not met, any progress for life expectancy and longevity would be futile (9).

Researchers believe that the concept of dynamic aging is accompanied with the increasing quantity of the elderlies' population and the quality of life and should be considered (10). There are various factors affecting dynamic aging including economic and behavioral factors, personality factors, physical environment, social and health factors. Each of them can have different impacts on elderlies' qualities of lives (11).

Today, due to the increasing indicator of longevity and life expectancy index, the important issue of how to pass the life "quality of life" has been proposed and has attracted the minds of pundits and researchers of ageing (12). Quality of life is a key indicator and encompasses aspects of life such as physiological factors and individual performance; so, it is of particular importance (13).

Non-admittance of elderlies in families has led to the increase of the number of nursing homes; therefore, the best alternative to take care of the majority of elderlies is nursing homes (6). In nursing homes, the ultimate goal of taking care of elderlies is to protect the quality of life. However, it is believed that due to the nature of life in such centers, it is assumed that they feel disappointed in life (14).

\section{Objectives}

This study compared the quality of life of elderlies in daycare and boarding nursing homes in Semnan, Iran and identified the differences in characteristics of quality of life. It can also help researchers to reduce the problems of elderlies.

\section{Materials and Methods}

This was a cross-sectional and analytic study conducted on elderlies over 60 years living in daycare and boarding nursing homes in Semnan. The samples were selected from day-care and boarding nursing homes in Semnan.

\subsection{Methods of Data Collection}

Gathering the data was carried out using the SF-36 questionnaire of quality of life among the elderlies. To assess the physical function, questions relating to vigorous activity, moderate activity, lifting and carrying, climbing stairs, bending and kneeling, walking and bathing were considered. To perform the role of physical function, questions about the limitation of daily activities, expected efficiency, and the amount of time spent on daily activities were used. To assess general understanding of health, there were questions about individual health compared with others, and to assess social activities questions about the individual's relationship with family, friends and relatives were considered. Scoring in the range of $0-100$ could have some fluctuations; zero represented the lowest level of quality and 100 showed the highest level.

The inclusion criteria used for people was being $\geq 60$ years and living in daycare and boarding nursing homes in Semnan. The exclusion criteria was those who did not have any cooperation or who had chronic psychiatric diseases, stroke, Alzheimer's disease and degenerative and debilitating diseases.

\subsection{Statistical Analysis Methods}

Data were analyzed using statistical package for social sciences (SPSS) 16. After distribution of variables and calculating the dispersion and central indices, to compare the means from the t-test and chi-squared test, KolmogorovSmirnov and Mann-Whitney tests, and to determine the correlation, numerical rating variables were used. In all the tests, the level of $\mathrm{P}<0.05$ was considered statistically significant.

\section{Results}

Based on the above tests, various aspects of quality of life among people living in daycare and homes were significantly different in subdivisions of quality of life in the areas of physical limitations $(\mathrm{P}<0.001)$, limitations of psycho-emotional function $(\mathrm{P}<0.001)$, energy and fatigue $(\mathrm{P}<0.008)$, psycho-emotional function $(\mathrm{P}<0.001)$, social function $(P<0.001)$, physical pain $(P<0.001)$, and public health $(\mathrm{P}<0.01)$. The differences were significant; but in the physical function area $(\mathrm{P}=0.437)$, the difference was not significant (Tables 1 and 2).

\section{Discussion}

To conclude the significant difference in different domains of quality of life, subtests of different domains were investigated: 
Table 1. Distribution of Demographic Information of Daily and Boarding Nursing Homes Residents ${ }^{\mathrm{a}}$

\begin{tabular}{|ccc|}
\hline Variable & $\begin{array}{c}\text { Boarding Nursing } \\
\text { Homes }\end{array}$ & Daily Nursing Homes \\
\hline Gender & $17(56.7)$ & $12(27.9)$ \\
\hline Male & $13(43.3)$ & $31(72.1)$ \\
\hline Female & & $7(16.3)$ \\
\hline Age, $\mathbf{y}$ & $9(30)$ & $36(83.7)$ \\
\hline$<70$ & $21(70)$ & $35(84.1)$ \\
\hline$>70$ & & $7(16.3)$ \\
\hline Education & $25(83.3)$ & $1(2.3)$ \\
\hline Illiterate & $4(13.3)$ & \\
\hline Elementary & $1(3.3)$ & $29(67.4)$ \\
\hline $\begin{array}{l}\text { High school } \\
\text { diploma }\end{array}$ & $30(100)$ & $14(32.6)$ \\
\hline Marital status & $27(90)$ & $43(100)$ \\
\hline Single & $3(10)$ & \\
\hline Married & & \\
\hline Total & & \\
\hline
\end{tabular}

${ }^{\mathrm{a}}$ Values are expressed as No. (\%).

Table 2. Mean and Standard Deviation of Variable in Daily and Boarding Nursing Homes $^{\mathrm{a}}$

\begin{tabular}{lccc}
\hline Variable & $\begin{array}{c}\text { Boarding } \\
\text { Nursing Homes }\end{array}$ & $\begin{array}{c}\text { Daily Nursing } \\
\text { Homes }\end{array}$ & PValue \\
\hline $\begin{array}{l}\text { Physical } \\
\text { restriction }\end{array}$ & $5.8 \pm 1.7$ & $4.2 \pm 0.5$ & $<0.001$ \\
$\begin{array}{l}\text { Emotional and } \\
\text { functional } \\
\text { limitation }\end{array}$ & $5.1 \pm 1.3$ & $4.1 \pm 1.1$ & $<0.001$ \\
\hline $\begin{array}{l}\text { Energy/fatigue } \\
\text { Psycho- } \\
\text { emotional } \\
\text { function }\end{array}$ & $14.4 \pm 2.9$ & $15.7 \pm 1.2$ & 0.008 \\
\hline $\begin{array}{l}\text { Social function } \\
\text { Physical pain }\end{array}$ & $16.5 \pm 2.2$ & $19.2 \pm 1.4$ & $<0.001$ \\
\hline \begin{tabular}{l} 
General health \\
\hline
\end{tabular} & $8.4 \pm 1.8$ & $6.4 \pm 1$ & $<0.001$ \\
\hline
\end{tabular}

${ }^{\mathrm{a}}$ Values are expressed as mean $\pm \mathrm{SD}$.

The domain of physical limitations included reducing the activity time and limitation in doing activity. The domain of psycho-emotional limitations included pain feeling in doing activities and the impact of pain on daily activities. In the domain of physical pain, which included pain sensation and the impact of pain on daily activities, the people who lived in boarding nursing homes gained higher scores in above items than those who were in day- care centers, showing a significant difference. This difference indicated that living in the closed space of boarding centers along with lack of communications with outside, low social contacts, being sedentary and decreased motivation are the items that need to be considered. The mentioned problems are approved by the following studies:

Vahdaninia et al. claimed that increased risk of chronic disease and reduced social contacts leads to isolation and loneliness in the elderly. Lack of social support and reduced autonomy due to physical and mental disabilities are factors that can lead to low quality of life (15). Based on the study by Jafarzade et al. elderlies needed their relatives or caregivers for daily activities, had a lower quality of life, and in fact, various signs indicated their need for nursing cares (16).

Liu and Gue carried out a study on Finnish people, showing that more than one third of the elderlies suffered from loneliness (17). Therefore, one of the potential risks on health in the elderly is loneliness and isolation (18).

A recent study indicated that people in daily centers gained much better scores than those who lived in boarding centers in energy, fatigue, psycho-emotional function, social performance and general health, showing a significant difference. Researchers believe that the main reason is more social interaction in daily centers than in boarding centers and also daily continuous family relationship with family members and relatives, lack of individual isolation, and being more active in daycare centers.

In a cross-sectional study by Panaghi et al. on elderlies' quality of life who lived with their families and those who lived in nursing homes in Tehran, they showed that the elderlies who lived with their families had a higher quality life in comparison with the group who lived in nursing homes. The mean scores of each three physical, mental and social functions among those who lived with their families were higher than the groups who lived in nursing homes (19).

Rana et al. showed that support of family and intergenerational relationships improved the quality of life among the elderly (20).

Song et al. indicated that mutual affection between parents and children had positive effects on health assessment of elderlies (21).

Sudha et al. showed that people who were involved in social support systems such as family, friends and peers were healthier and experienced a greater satisfaction in their lives and lived a longer life (22).

de Moraes and de Azevedo e Souza compared the quality of family relationships between two genders. The results showed that women with good family and social relationships and with perception of health, also having adequacy in performance and psychosocial support, had 
successful aging. In men, perception of the adequacy of performance, friendship and family relationships led to a greater aging (23).

The results showed that people living in daycare centers had better quality of life physically and mentally. Therefore, to improve their qualities of lives in physical and mental domains among the elderlies in boarding nursing homes, the family relationship inside and outside the nursing homes along with plans to meet the psychoemotional needs besides physical conditions such as mobility and balance should be considered.

\section{Acknowledgments}

We are grateful to all the elderlies who participated in this study, as well as everyone who helped us to conduct this study.

\section{Footnote}

Authors' Contribution: All Authors were equally involved in study concept and design, acquisition of data, analysis and interpretation of data, drafting of the manuscript, critical revision of the manuscript for important intellectual content, statistical analysis, administrative, technical, and material support, and study supervision.

\section{References}

1. Eshaghi SR, Shahsanai A, Ardakani M. Assessment of the Physical Activity of Elderly Population of Isfahan, Iran.J Isfahan Med School. 2011;29(147).

2. Dadkhah A. The system of geriatric services in the United States and Japan and some components provide strategic planning services for elderly in Iran. Iran J Ageing. 2007;2(3):167.

3. Nesbitt BJ, Heidrich SM. Sense of coherence and illness appraisal in older women's quality of life. Res Nurs Health. 2000;23(1):25-34. [PubMed: 10686570].

4. Johnson RA, Tripp-Reimer T. Aging, ethnicity, social support. A reviewpart 1.J Gerontol Nurs. 2001;27(6):15-21. [PubMed: 11915115].

5. Ahmadi F, Salar A, Faghihzadeh S. Assessing quality of life among elderly people in Zahedan. Hayat. 2004;10(22):61-7.

6. Harrefors C, Savenstedt S, Axelsson K. Elderly people's perceptions of how they want to be cared for: an interview study with healthy elderly couples in Northern Sweden. Scand J Caring Sci. 2009;23(2):35360. doi: 10.1111/j.1471-6712.2008.00629.x. [PubMed: 19645809].
7. Canbaz S, Sunter AT, Dabak S, Peksen Y. The prevalence of chronic diseases and quality of life in elderly people in Samsun. Turk J Med Sci. 2003;33(5):335-40.

8. Simonetti JP, Ferreira JC. [Coping strategies developed by caregivers of elderly with chronic diseases]. Rev Esc Enferm USP. 2008;42(1):19-25. [PubMed: 18450143].

9. Kim JH, Knight BG. Effects of caregiver status, coping styles, and social support on the physical health of Korean American caregivers. Gerontologist. 2008;48(3):287-99. [PubMed: 18591354].

10. Alipour F, Sajadi H, Forouzan A, Biglarian A. The role of social support in elderly quality of life. Salmand J. 2009;4(11):53-60.

11. Albou KM, Ramezani MA, Arizi F. A study on the quality of life among elderly Shahinshahr area of Isfahan province in year 2004. Jundishapur Sci Med J. 2007;5(51):701-7.

12. Ahmadi F, Salar A, Faghihzadeh S. Quality of life in Zahedan elderly population. Hayat. 2004;10(3):61-7.

13. Habibi Soula A, Nkpour S, Seyed Alshohadaei M, Haghani H. Health promotion behaviors and quality of life among elderly people.JAUMS 2008;8(27):29-36.

14. Lee LY, Lee DT, Woo J. Tai Chi and health-related quality of life in nursing home residents. J Nurs Scholarsh. 2009;41(1):35-43. doi: 10.1111/j.1547-5069.2009.01249.x. [PubMed: 19335676].

15. Vahdaninia MS, Gashtasebi A, Montazeri A, Maftoon F. Health related quality of life in the the elderly: a population study. Payesh. 2004;2:113-20.

16. Jafarzade FM, Behnam VH, Vahedian M. The quality of life of the elderly in Sabzevar, Iran. Sabzevar Med Sci J. 2010.

17. Liu LJ, Guo Q. Loneliness and health-related quality of life for the empty nest elderly in the rural area of a mountainous county in China. Qual Life Res. 2007;16(8):1275-80. doi: 10.1007/s11136-007-92500. [PubMed: 17703375].

18. Tan SJ, Tambyah SK, Kau AK. The influence of value orientations and demographics on quality-of-life perceptions: Evidence from a national survey of Singaporeans. Soc Indicat Res. 2006;78(1):33-59.

19. Panaghi L, Abarashi Z, Mansoori N, Dehghani M. Quality of Life and Related demographic factor of the elderly in Tehran. Iran J Ageing. 2010;4(2).

20. Rana AK, Wahlin A, Lundborg CS, Kabir ZN. Impact of health education on health-related quality of life among elderly persons: results from a community-based intervention study in rural Bangladesh. Health Promot Int. 2009;24(1):36-45. doi: 10.1093/heapro/dan042. [PubMed: 19136677].

21. Song L, Li S, Zhang W, Feldman M. Integrated support and selfrelated health of the elderly in a rural area in China. Healt longevity. 2008;20:33-42.

22. Sudha S, Suchindran C, Mutran EJ, Rajan SI, Sarma PS. Marital status, family ties, and self-rated health among elders in South India. $J$ Cross Cult Gerontol. 2006;21(3-4):103-20. doi:10.1007/s10823-006-9027x. [PubMed: 17242992].

23. de Moraes JF, de Azevedo e Souza VB. Factors associated with the successful aging of the socially-active elderly in the metropolitan region of Porto Alegre. Rev Bras Psiquiatr. 2005;27(4):302-8. [PubMed: 16358112]. 